\title{
Bad Romance: Exploring the Factors That Influence Revenge Porn Sharing Amongst Romantic Partners
}

\author{
Joseph M. Sirianni, Niagara University, USA \\ Arun Vishwanath, University at Buffalo SUNY, USA
}

\begin{abstract}
The study of revenge in a romantic context has steadily gained traction in the social sciences. Researchers have been interested in exploring what influences romantic revenge, but most studies have failed to specify the type of romantic revenge individuals carry out and also ignored the impact of technology on the enactment of revenge. The current study addressed these issues using social cognitive theory by examining a specific type of romantic revenge enabled by technology-revenge porn. Revenge porn is the nonconsensual sharing of a romantic partner's sexual images through the Internet or mobile phones. Although this behavior has been widely covered by the mainstream media, it has been largely ignored by the scientific community. Two provocation conditions (high severity and low severity) were designed to act as a stimulus to elicit responses from participants. Following exposure to one of the provocation stimuli, participants $(\mathrm{N}=200)$ answered questions designed to examine the motivations that were most likely to lead them to participate in disseminating revenge porn. Results reveal that dispositional vengefulness, vicarious experience, and expected outcomes played a role in predicting the likelihood for sharing revenge porn. Implications for future research on revenge porn are discussed.
\end{abstract}

Keywords: revenge porn, romantic revenge, revenge, social cognitive theory 


\section{Introduction}

Bad romance: Exploring the factors that influence revenge porn sharing amongst romantic partners

Since its rise in popularity the Internet has offered its users several sexual outlets including bulletin board systems, Usenet groups, e-mail, chat rooms, web cams, and most recently social media sites. These forms of online communication have enabled individuals to converse and express themselves with unbridled sexual freedom. Over the past few years, the technological merging of the Internet and mobile phone devices have further advanced sexual communication allowing not only easier access to pornographic content but also a more convenient way to create and distribute self-produced pornography. Today, Internet platforms, mobile phones and text messaging services make the everyday person capable of being an instant producer enabling them toupload sexual images of themselveseither privately or publicly. Research on this technologically-driven sexual behavior shows that about a third of young adults 20-26 and $20 \%$ of teens say they've created and shared naked photos or videos of themselves online (Jayson, 2008).

Althoughsharing onlinesexual media can offer content creators a variety of beneficial outcomes including sexual acceptance, increased happinessand social inclusion (Boies, 2002; Diamond, 2009; Doring, 2009; Innala, 2007; Authors, 2012), particular attention has been devoted to researching the negative aspects of Internet porn such as online addiction and compulsivity, risky online and offline sexual behaviors, and the consumption of illegal pornographic material (Couch \& Liamputtong, 2007; Grov, 2004; Levin, Lillis, \& Hayes, 2012; Liau et al., 2006; Bull et al., 2004; Philaretou, Mahfouz, \& Allen, 2005; Twohig, Crosby \& Cox, 2009).

Most recently, a new phenomenon known as revenge porn, has joined the list of potentially negative behaviorsengendered by the mergingof the Internet and pornography. Revenge pornis defined as the vengeful online distribution of a person's sexual images without their permission (Franks, 2013).In its most basic form, a person in a romantic relationship willingly creates and sends a sexually explicit image of themselvesthrough a mobile phone or the Internet to their romantic partner. The image may serve to benefit their relationship initially, but in the event of 
a romantic provocation (i.e. infidelity, relationship dissolution), that image may be deliberately redistributed to other individualsas a way to get even with their partner.

Aside from one academic article by Stroud (2014) that presented a critique of the revenge porn phenomenon, scientific research appears to be nonexistent. A published report by the Cyber Civil Rights Initiative "Effects of Revenge Porn" Survey (2013) attempted to reveal several alarming facts about revenge porn. The opt-in survey, however, was heavily skewed towards a female demographic as stated and ignored previous research that used a nationwide sample and showed that men were slightly more likely than women to be victims of revenge porn (see McAfee, "Lovers Beware", 2013). Additionally, the study also compiled results from the McAfee "Lovers Beware" study to reach its conclusion. It should be noted that the McAfee study additionally, was not scientifically explored and did not come from an academic publication. The topic of revenge porn thus begs for new research that is both scientifically grounded and theoretically based.

The media has also devoted a significant amount of attention in covering revenge porn activities which lends evidence to its notable salience. A search of the term revenge porn in the Factiva database produces 1,695 worldwide published stories in the past year and a primary focus of the media has been devoted towards condemning this behavior (Stroud, 2014). Aside from news stories intended to combat revenge porn sharing, social media outlets such as Reddit and Twitter have banned the publication of revenge porn content on their respective sites. In addition to the media, policy makers have also displayed efforts in reproaching this behavior. Presently, 28 states have introduced or have pending laws to incriminate the nonconsensual sharing of sexually explicit content (National Conference of State Legislatures, 2014). Notable cases dealing with the legality of revenge porn include the approval of laws banning revenge porn in Israel, Britain and Wales; a landmark case in San Diego that resulted in the first conviction of an operator of a revenge porn website; and the trial of ex-NFL player, Jermaine Cunngiham, who recently pleaded guilty to revenge porn accusations.

The phenomenon of revenge porn fits into a relatively new area of revenge research - romantic revenge. Research has demonstrated that higher expectations are often attached to romantic 
relationships due to the provisions they carry such as intimacy, emotional support, security, exclusive commitment, passion and sex (Connolly, Craig, Goldberg, \&Pepler, 1999; Flannagan, Marsh, \& Furhman, 2005; Hazan \& Shaver, 1987; Shaver \& Mikulincer, 2006). Because of the stakes that are invested in romantic relationships, it is not surprising that individuals react vengefully when they are subject to provocations by their partners. The research on romantic revenge has become more popular over the past decade or so; however, much still needs to be done in examining the goals and influences behind specific types of revenge responses (for exceptions see Boon, Deveau, \& Alibhai, 2009; McDonald \& Asher, 2013; Yoshimura, 2007).

Due to the minimal amount of non-scientific research that has been conducted on revenge porn and the growing concern for it, this study aims to examine the various factors that drive individuals in romantic relationships to engage in revenge porn sharing. Furthermore, unlike the majority of past romantic revenge studies, this study specifically examines romantic revenge as a technologically mediated form of revenge. Presently, the ways in which people communicate has been drastically influenced by the rapid proliferation and adoption of new technologies (Kane, Alavi, LaBianca, \& Borgatti, 2014) making sexual content of other individuals easy to store and share to mass audiences with the click of a button (Buzzell, 2005). Technology such as e-mail, social media sites and text messaging services thusmake revenge porn a quick and easy route for retribution, paving the way for greater victim humiliation and greater satisfaction for the revenge porn participant. The next section presents the theoretical framework followed by the research model.

\section{Theoretical Framework}

To understand what motivates individuals to engage in revenge porn sharing, social cognitive theory (Bandura, 1986) will be utilized. Social cognitive theory (SCT) examines human functioning under a complex, multidimensional framework. The theory specifically examines how behavior is maintained and acquired as a result of external and internal influences.

Studies using SCT to explain revenge motivations remain few and far between. Particular focus has been on using SCT to examine workplace revenge (Brees, Mackey, \& Martinko, 2013; 
Douglas \& Martinko, 2001; Glomb \& Liao, 2003; Restubog, 2012; Seabright \& Schminke, 2002) analyzing vengeful behaviors in adolescents (Errante, 2003; Kotler \& Calverf, 2005; Linkroum, 2009; Runions, 2013) and exploring how the media shapes our perceptions of revenge (Deveau \& Fouts, 2005; Dickerman, Christensen, \& Kerl McClain, 2005; Zehnder \& Calvert, 2008). To date, using SCT as a framework to explain romantic revenge is nonexistent.The present manuscript uses SCT to examine the factors that are most likely to influence individuals to share revenge porn of their romantic partner following a provocation. These factors include internal factors such asexpected outcomes, dispositional vengefulness, technological self-efficacy, and external factors such as vicarious experience and provocations.

\section{Hypotheses}

Within SCT, behavior is primarily motivated by the expected outcomes of a given behavior. Expected outcomes are described as behavioral incentives that serve to motivate and guide behavior (LaRose \& Eastin, 2004). Research shows that revenge behaviors that occur in a relational context are often influenced by the desire to obtain goals (Yoshimura, 2007). Rasmussen (2013) states that the more individuals believe revenge is likely to produce positive outcomes, the more they should perceive revenge as an effective response to romantic provocations. Furthermore, although romantic revenge seekers may project certain negative outcomes as a result of retaliatory actions, they tend to place more value on the positive outcomes (Sheppard \& Boon, 2012).

A major motivation for seeking revenge goals in romantic relationships as described by Boon, Deveau and Alibhai (2009) is the need to cause desired changes in their transgressor's attitudes, feelings or behaviors. These involve motives for making their partners feel regret, empathy, humiliation, and suffering for their initial offense. Additional underlying rewards associated with this type of revenge include the need to punish their partner, to teach them a lesson,and to damage their self-image (Baumeister, 1997; Bies et al., 1997). Furthermore, individuals who feel devalued and disempowered often seek revenge against romantic partners to alleviate negative feelings following a provocation (Boon, Alibhai, \& Deveau, 2011). Revenge methods are often likely to occur when an individual's reputation or social position is harmed (Yoshimura, 2007) and may be motivated by outcomes such as repairing one's ego, reputation, 
self-esteem, and power after experiencing a transgression (Baumeister, 1997; Bies, Tripp, \& Kramer; Frijda, 1994).

This study therefore, presents two types of expected outcomes that are predicated on seeking revenge: Partner-directed outcomes that describe goals intended to cause a change in their romantic partners' attitudes, feelings, or behaviors after a provocation and self outcomes that describe goals associated with getting revenge to alleviate negative feelings one has following a romantic provocation.

H1: Expected partner and self-outcomes will be positively related to the likelihood to share revenge porn.

Under SCT, the framework of reciprocal determinism explains how behavioral, psychological and environmental factors influence each other in a multi-directional manner. Research demonstrates that vengefulness cannot only be viewed as an emotion, but also as a psychological dynamic that is part of a person's way of being (Gabriel \& Monaco, 1994). Work by McCullough et al. (2001) suggests that people who are less forgiving after an interpersonal transgression may have an inherent disposition to be more vengeful than others (McCullough et al., 2001). Dispositions according to Bandura (1986) are enduring personality traits that govern human behaviors and vengefulness is the disposition to respond to an interpersonal offense with vengeful actions (McCullough et al., 2001). People who are dispositionally vengeful are more likely to see the benefits of getting revenge as opposed to seeing the detrimental costs of revenge because of their unwillingness to compromise when faced with a provocation (Sheppard \& Boon, 2012). Moreover, vengeful individuals who retaliate against romantic partners have been known to experience positive feelings following a retributive act (Boon et al., 2011). Ultimately, individuals who are dispositionally vengeful have a tendency to maintain vengeful motivations towards transgressorsand are more likely to seek the positive outcomes of revenge (McCullough et al., 2001).

H2: Vengefulness will be positively related to partner and self-outcomes. 
Self-efficacious beliefs allow individuals to successfully assess motivations, cognitive resources and courses of action when responding to given events (Benight \& Bandura, 2004; Ozer \& Bandura, 1990). Factors that drive an individual's motivation for a particular behavior are grounded in the core belief that one has the power to produce the desired outcomes of one's actions (Benight \& Bandura, 2004).

In the current context, scorned individuals in romantic relationships may be motivated by a series of goals to share revenge porn of their partner and these goals are partly determined by their self-efficacious beliefs for using the technology to share revenge porn. In a study by LaRose and Eastin (2004), participants who had higher self-efficacious beliefs for Internet use had higher expectations for obtaining specific Internet outcomes.It is also predicted that individuals who have high technological self-efficacy for sharing revenge porn will also be more likely to have higher expectations for achieving the rewards of sharing revenge porn. Potential revenge porn disseminators must understand how to find sites online that cater to revenge porn content and also must know how to upload and share such content either through the computer or mobile devices to achieve desired outcomes. Those people who have the technological capability for sharing revenge porn are therefore most likely to hold high selfefficacious beliefsfor obtaining expectedpartner and self-outcomes.

H3: Technological self-efficacy will be positively related to expected partner and self outcomes.

The most predominant individuals in a social circle are likely to have the most influence on which behaviors are selectively activated (Bandura, 2009). Positive rewards described by peers who have participated in revenge porn are likely to influence the potential for others to share in the future. Accordingly, the actions of others become a powerful source of behavioral modeling when the observer predicts an acquirement of positive outcomes by engaging in similar conduct (Bandura, 2009). People who learn that peers have achieved positive outcomes by sharing revenge porn should be more likely to model these behaviors and predict achievement of the same outcomes. 
People who visit revenge porn sites such as MyEx.com may alsobe likely to share revenge porn based on the positive outcomes depicted by the uploaders of these sites. On these sites, offended people are encouraged to share nude photos of their ex-lovers with accompanying descriptions and stories behind their failed relationships. Posters are likely to inform visitors about the goals they have obtained from uploading their partner's images such as humiliating them, ruining their reputation, and making them suffer. By observing these positive outcomes on revenge porn web sites, individuals may be influenced to share revenge porn of their romantic partners following a provocation.

H4: Vicarious experience will be positively related to partner and self-outcomes.

H5: Vicarious experience will be positively and directly related to the likelihood to share revenge porn.

Provocations are the events that influence one's motivation to carry out revenge against their perceived offender (Bies \& Tripp, 1996; McLean-Parks, 1997; Nathanson, Williams, Paulhus, 2004). Moreover, across numerous studies, those who engage in revenge always report taking action in response to a provocation enacted by someone else (see Tripp \& Bies, 1997 for a complete review). Hence, provocation type was included as a moderator in the hypothesized model.

Research has revealed several provocations that may impel individuals to engage in revenge against their romantic partner including ignoring emotional needs, damaging personal property, relationship dissolution, infidelity, and disclosure of personal information (Boon, Deveau \& Alibhai, 2009). Although some individuals may perceive different types of provocations as more damaging to a relationship than others, vengeful responses are more likely to be attributed to the perceived severity of the provocation (Finkel et al., 2002). Hypotheses 1 and 5 posit a significant relationship from their respective constructs (expected outcomes and vicarious experience) and the likelihood to share revenge porn. These relationships are expected to be moderated by how one will determine the intensity of the provocation. The following moderated relationships are thus hypothesized: 
H6a: Expected partner and self-outcomes and the likelihood to share revenge porn will be moderated by the perceived severity of a provocation such that those individuals who are more provoked by a partner's transgression will be more likely to share revenge porn of their partner than individuals who are less provoked by their partner.

H6b: Vicarious experience and the likelihood to share revenge porn will be moderated by the perceived severity of a provocation such that those individuals who are more provoked by a partner's transgression will be more likely to share revenge porn of their partner than individuals who are less provoked by their partner.

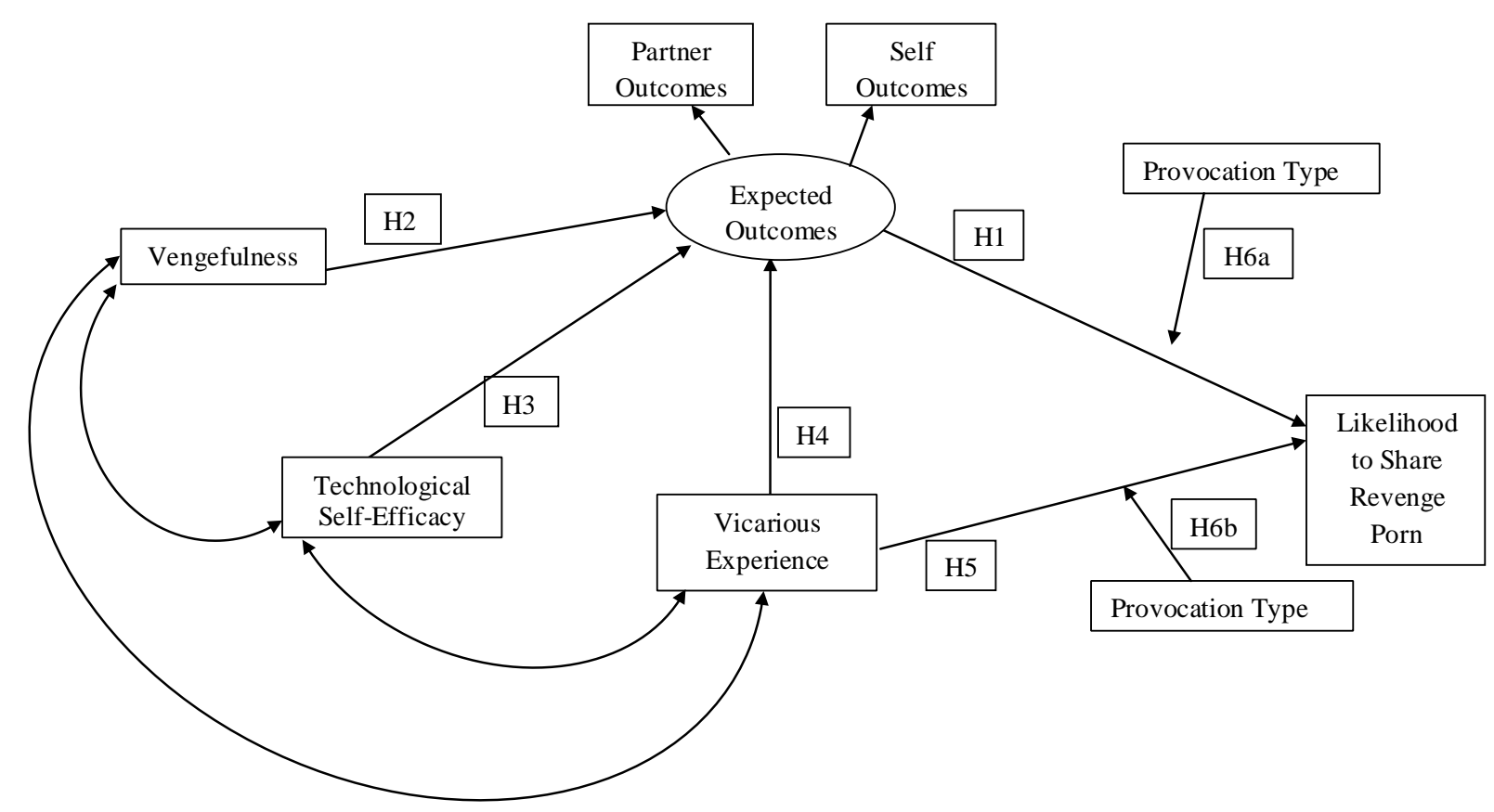

Figure 1. Hypothesized model 


\section{Method}

\section{Participants}

Participants consisted of 200students (116 males, 95 females) enrolled in anintroductory undergraduate Communication course at a large Northeastern university. All subjects received course credit for their participation. Subjects agreed to participation via an online consent form. Participants were guaranteed complete anonymity and all data was used by the authors for the purpose of this study only.

Research by McDonald and Asher (2013) shows that college students are more likely to enact revenge on romantic partners than other individuals in their life when transgressed against (McDonald \& Asher, 2013). In that study, college students were asked to respond to several revenge-inducing scenarios in three different contexts involving friends, roommates and romantic partners. Participants were more likely to endorse hostile goals and strategies with romantic partners than in the other contexts. This could be attributed to the high expectations of intimacy, support and exclusive commitment in most college relationships (Flannagan, Marsh \& Furhman, 2005). College students also typically have that "my one and only" relationship mentality that may increase an individual's tendency to negatively react to transgressive behaviors (Flannagan et al., 2005; McDonald \& Asher, 2013). Sending sexual images through mobile technologies is a common behavior amongst college students in romantic relationships (Drouin \& Landgraff, 2012) and 20\% of teens and $31 \%$ of young adults report to sharing sexual images of themselves (Jayson, 2008). These findings thus make analyzing college students in the current context an appropriate population to analyze.

\section{Measures}

An online questionnaire created by the research investigator was created to collect data for both conditions. The majority of constructs in the study were measured using 5-point Likert type scales ranging from 'strongly disagree' to 'strongly agree' unless otherwise noted. Because of the possibility that the hypothetical provocations could influence respondents' dispositional vengefulness, participants' vengefulness was measured at the start of the survey. Wherever possible, the scales used for the instrument were taken from previously validated measures, reworded and designed to fit within the context of the study. 
Expected outcomes. 12-items created by Boon, Deveau and Alibhai (2009) were used to measure two dimensions of revenge outcomes: partner directed outcomes (e.g. "make your partner regret what they did") and self-directed outcomes (e.g. "regain your self-respect").

Vengefulness. 10- items from the Vengeance Scale (Stuckless \& Goranson, 1992) was used to assess individuals' attitudes toward vengeance (e.g. "I don't just get mad, I get even") and their proneness to engage in revenge (e.g. "anyone who provokes me deserves the punishment that I give them").

Technological Self-Efficacy. A 6-item scale created by the author was generated to measure participants" capability to use the technology to share revenge porn (e.g. "I feel confident in my ability to share pictures on revenge porn web sites").

Vicarious Experience. A 3-item scale created by the author was used to measure the external influences that might lead individuals to share revenge porn of their partner (e.g. "I saw revenge porn images on a web site", "I know someone who has shared revenge porn").

Revenge Porn Sharing: A single question that asked individuals how likely they would be to share revenge porn of their partner were used to assess participants' likelihood for sharing revenge porn.

\section{Materials and Procedure}

In order to test for the moderating effect of provocations, participants were assigned to a high severity $(\mathrm{N}=100,59$ males, 41 females $)$ or low severity condition $(\mathrm{N}=100,64$ males, 36 females) that described a provocation by a romantic partner.Past research has shown that the severity of a provocation is often a harbinger for how angry and vengeful the response will be (Barners, Brown, \& Osterman, 2007; Cloke, 1993; Leary, Koch, \& Hechenbleikner, 2001; Roseman, Wiest, \& Swartz, 1994).

At the start of the questionnaire, participants read two vignettes that represented a high provocation or a low provocation modeled after a study by Gunderson and Ferrari (2008). 
Because research offers an extensive array of potential provocations that can lead to romantic revenge (Metts\&Cupach, 2007; Yoshimura, 2007; Boon,Deveau, \&Alibhai, 2009) it was important to concentrate on a minimum set of provocations to reduce any skewed variability in this study. Moreover, to ensure that the high and low provocations differed in severity, it was important that the high provocation vignette depict a serious affront to ones romantic relationship. The high provocation condition described a situation that involved infidelity between two romantic partners. Because infidelity has been known to be a major provocation for triggering revenge (Boon, Deveau, \& Alibhai, 2009;Ohbuchi, Kameda, \& Agarie, 1989; Rassmusen\& Boon, 2013; Yoshimura, 2007), it was selected as the provocation in the high condition. Selecting a situation for the low provocation condition that also depicted the crossing of relational boundaries (i.e. catching a partner texting another romantic partner) potentially ran the risk of participants also indicating high levels of anger and would thus reduce variance within subjects.

The high provocation vignette read as follows:

Imagine that you are currently romantically involved with someone. The two of you have an established relationship, and you comfortably refer to your partner as your "boyfriend" or "girlfriend." You and your partner spend a great deal of time together, and both of you are content with the relationship. One day, you come home to find your partner having sex with another person. You were previously unaware of this behavior.

For the low provocation condition, participants read a situation in which an individual forgets to call their romantic partner after promising to do so earlier in the day. Although Metts and Cupach (2007) describe broken promises as a cause of revenge, this situation was expected to be much less serious compared to the infidelity vignette.

The low provocation vignette read as follows:

Imagine that you are currently romantically involved with someone. The two of you have an established relationship, and you comfortably refer to your partner as your "boyfriend" or "girlfriend." You and your partner spend a great deal of time together, and both of you are 
content with the relationship. One day your partner tells you that they will call you at a specific time of the day to talk to you. When that time arrives, you do not hear from your partner. You decide to call them instead and when they answer your partner tells you they completely forgot to call you.

Provocations within romantic relationships are subject to variability in terms of how one interprets the severity of the event (Morse and Metts, 2011); therefore, a manipulation check of emotional anger wasincluded at the end of each vignette. The manipulation consisted of one item measured on a 10-point likert scale ranging from 1 (not angry) to 10 (extremely angry). In the high provocation condition, participants were asked: "How angry would you feel after you found your romantic partner cheating on you?" Participants in the low provocation condition were asked: "How angry would you be after your romantic partner forgets to call you on the phone?"An independent samples t-test found a significant difference between the means of the two groups $(t(198)=11.609, p<.05)$. The mean of the high provocation group was significantly higher $(\mathrm{m}=9.26$, $\mathrm{sd}=1.46)$ than the mean of the low provocation group $(\mathrm{m}=$ 5.59, $\mathrm{sd}=2.80)$.

To eliminate any bias within participants, gender was controlled for in the study.Revenge porn has often been framed as an act that is intended to shame, humiliate, and destroy the lives of young females (Filipovoc, 2013). Citron and Franks (2014) also add that the majority of cases involving revenge porn are presented as narratives that depict females as the victims and males as the perpetrators. For these reasons, it was necessary to control for any influence that gender may have had on the variables being tested.

\section{Data Analysis}

Partial least square structural equation modeling (PLS-SEM) analysis was used to estimate the hypothesized model using Smart PLS software (Ringle et al., 2013). PLS-SEM is similar to covariance structural equation modeling (CB-SEM) techniques in that it uses multiple regressions to predict the values for latent variables and explicitly recognizes measurement error (Bhakar et al, 2012; Chin \& Newsted, 1999; Fornell\& Cha, 1994; Chin, 1998; Fornell\&Bookstein, 1982). On the other hand, PLS-SEM is less restrictive than CB-SEM and 
can be used with smaller sample sizes and can be measured with constructs containing fewer items (Fornell \& Cha, 1994; Henseler et al., 2014; Reinartz, 2009). PLS-SEM therefore, served as an appropriate method to analyze our sample of 200 participants. Pertinent to the current study, PLS-SEM has notably been recently applied in the field of sexual research byAuthors (2015).

PLS-SEM is designed to maximize the explained variances of the model's dependent constructs. The PLS model is analyzed in two stages. First the measurement model is evaluated which provides estimates for the validity and reliability of the construct measures in the model (Bhakar et al., 2012). This analysis is performed to ensure that the constructs being measured are reliable and valid for assessment of the overall structural model. During the second stage, calculations are produced that reveal the final estimates of the outer weights and loadings as well as the structural model's path coefficients.

\section{Reliability}

Individual item reliability was tested for each construct by extracting the factor loadings of all indicator items to their appropriate constructs (Chin, 1998). All items exceeded the cut-off value of 0.50 as recommended by Hulland (1999). In addition to Cronbach's alpha, Fornell and Larcker's (1981) measure of composite reliability was estimated to determine the constructs' reliability. The composite reliabilities of the different measures range from 0.81 to 0.97 which satisfies the recommended cut-off value of 0.70 (Nunnally, 1978).

\section{Convergent Validity}

Results for the convergent validity test indicated that the AVE for the five scales ranged from 0.60 to 0.85 which satisfies the cut-off value of .50 as set byFornell and Larcker (1981).These findings support the notion that all items are related to their respected constructs. Individual factor loadings, Cronbach's alpha, composite reliabilities, and average variance extracted values can be found in Table 1 . 
Volume: 6 - Issue: 4 October - 2016

Table 1. AVE, Composite Reliability, Cronbach's Alpha

\begin{tabular}{|c|c|c|c|c|}
\hline & Factor Loadings & AVE & Composite Reliability & Cronbach's Alpha \\
\hline Technological Self Efficacy & & 0.79 & 0.97 & 0.97 \\
\hline Self_Eff_1 & .931 & & & \\
\hline Self_Eff_2 & .933 & & & \\
\hline Self_Eff_3 & .956 & & & \\
\hline Self_Eff_4 & .971 & & & \\
\hline Self_Eff_5 & .971 & & & \\
\hline Self_Eff_6 & .948 & & & \\
\hline Partner Outcomes & & 0.81 & 0.96 & 0.95 \\
\hline Part_1 & .881 & & & \\
\hline Part_2 & .903 & & & \\
\hline Part_3 & .919 & & & \\
\hline Part_4 & .889 & & & \\
\hline Part_5 & .913 & & & \\
\hline Part_6 & .906 & & & \\
\hline Self Outcomes & & 0.84 & 0.97 & 0.96 \\
\hline Self_1 & .857 & & & \\
\hline Self_2 & .937 & & & \\
\hline Self_3 & .920 & & & \\
\hline Self_4 & .954 & & & \\
\hline Self_5 & .932 & & & \\
\hline Self_6 & .918 & & & \\
\hline
\end{tabular}


Volume: 6 - Issue: 4 October - 2016

\begin{tabular}{|c|c|c|c|c|}
\hline Vengefulness & & 0.63 & 0.94 & 0.93 \\
\hline Veng_1 & .815 & & & \\
\hline Veng_2 & .828 & & & \\
\hline Veng_3 & .767 & & & \\
\hline Veng_4 & .780 & & & \\
\hline Veng_5 & .761 & & & \\
\hline Veng_6 & .833 & & & \\
\hline Veng_7 & .657 & & & \\
\hline Veng_8 & .870 & & & \\
\hline Veng_9 & .832 & & & \\
\hline Veng_10 & .812 & & & \\
\hline Vicarious Experience & & 0.60 & 0.81 & 0.71 \\
\hline Vic_1 & .816 & & & \\
\hline Vic_2 & .671 & & & \\
\hline Vic_3 & .820 & & & \\
\hline
\end{tabular}

\section{Discriminant Validity}

Tests for discriminant validity satisfied both criterion described by Chin (1998) and Bhakar et al. (2012).All constructs had an AVE loading greater than 0.5 and all values reported in the tablewere significantly higher than the off-diagonal values in the corresponding rows and columns. The confirmation of both criteria lends evidence that the constructs vary adequately. Discriminant validity results can be found in Table 2. 
Table 2. Discriminant validity

\begin{tabular}{lcccccc}
\hline & $\begin{array}{c}\text { Technological } \\
\text { Self Efficacy }\end{array}$ & $\begin{array}{c}\text { Partner } \\
\text { Outcomes }\end{array}$ & $\begin{array}{c}\text { Self } \\
\text { Outcomes }\end{array}$ & Sharing & Vengefulness & $\begin{array}{c}\text { Vicarious } \\
\text { Influence }\end{array}$ \\
\hline Technological Self & & & & & & \\
Efficacy & $\mathbf{0 . 8 9 3 9}$ & & & & & \\
Partner Outcomes & 0.1973 & $\mathbf{0 . 9 0 2 2}$ & & & & \\
Self Outcomes & 0.2048 & 0.8056 & $\mathbf{0 . 9 2 0 2}$ & & & \\
Sharing & 0.3145 & 0.6071 & 0.5739 & $\mathbf{1}$ & & \\
Vengefulness & 0.2303 & 0.4747 & 0.4619 & 0.5571 & $\mathbf{0 . 7 9 7 4}$ & \\
Vicarious Experience & 0.2487 & 0.1963 & 0.1848 & 0.2955 & 0.3583 & $\mathbf{0 . 7 7}$ \\
\hline
\end{tabular}

\section{Results}

Significant tests of the hypotheses and t-values were tested by computing path coefficients $(\beta)$ using Smart PLS (Ringle, 2005). To evaluate the statistical significance of the path coefficients, the bootstrapping method was used. Since PLS-SEM does not assume normal distributional data for parameter estimation, fit indices traditionally found in CB-SEM models such as the root mean square error approximation or comparative fit indices are not calculated or reported (Chin, 1998).

The overall hypothesized model $(\mathrm{N}=200)$ predicted $43 \%$ of the variance in the dependent variable (likelihood to share revenge porn). The variance explained for each of the endogenous variables was as follows: partner outcomes $\left(\mathrm{R}^{2}=.249\right)$, self-outcomes $\left(\mathrm{R}^{2}=.247\right)$, vengefulness $\left(\mathrm{R}^{2}=.085\right)$, technological self-efficacy $\left(\mathrm{R}^{2}=.057\right)$, and vicarious experience $\left(\mathrm{R}^{2}=.024\right)$. The hypothesized relationships, their path coefficients, and p-values can be found in Table 3.

Hypothesis 1 predicted a relationship between expected partner and self-outcomes and the likelihood to share revenge porn. The path from expected partner outcomes to the likelihood to share revenge porn was supported. The path from expected self-outcomes to the likelihood to share revenge porn was not supported. Hypothesis 2 predicted a relationship between vengefulness and expected partner and self-outcomes. This relationship was supported. Hypothesis 3 predicted a relationship between technological self-efficacy and expected partner and self-outcomes. This relationship was not supported. Hypothesis 4 predicted a relationship 
between vicarious experience and expected partner and self-outcomes. This relationship was not supported. Hypothesis 5 predicted a relationship from vicarious experience and the likelihood to share revenge porn. This relationship was supported.

Moderating effects were predicted in hypothesis $6 \mathrm{a}$ and $6 \mathrm{~b}$. A significant effect was not found between the two groups for the path between expected partner outcomes and the likelihood to share revenge porn as predicted. A significant effect was found between the path from expected self-outcomes and the likelihood to share revenge porn for those individuals in the low provocation group, however.A significant difference was not found between the two groups for the path from vicarious experience and the likelihood to share revenge porn.

Table 3. Hypotheses and structural model results of the hypothesized model

\begin{tabular}{cllll}
\hline & & Path & Path Coefficients & Moderation Results \\
\hline H1 & Sharing & $\leftarrow$ Partner Outcomes & $.381^{*}$ & H6a \\
& Sharing & $\leftarrow$ Self Outcomes & .236 & H6a* \\
H2 & Partner Outcomes & $\leftarrow$ Vengefulness & $.480^{* * *}$ & - \\
& Self Outcomes & $\leftarrow$ Vengefulness & $.474^{* * *}$ & - \\
H3 & Partner Outcomes & $\leftarrow$ Self Efficacy & .109 & - \\
& Self Outcomes & $\leftarrow$ Self Efficacy & .126 & - \\
H4 & Partner Outcomes & $\leftarrow$ Vicarious Experience & .017 & - \\
& Self Outcomes & $\leftarrow$ Vicarious Experience & .007 & - \\
H5 & Sharing & $\leftarrow$ Vicarious Experience & $.159^{*}$ & H6b \\
\hline
\end{tabular}

$* \mathrm{p}<0.05 ; * * * \mathrm{p}<0.001$

Note: --- indicates non-hypothesized relationship under moderation results

\section{Discussion}

The purpose of this study was to use SCT to explore the factors that influence people to share revenge porn of their romantic partners following a partner's provocation. Results lend partial support to the overall structure of the model: Partner outcomes predicted the likelihood to share revenge porn; vengefulness predicted partner and self-outcomes; and vicarious experience 
predicted the likelihood to share revenge porn.Although the findings of H6a and H6b were not confirmed, the results of H6a produced compelling results that are discussed further below.

It was predicted that expected partner and self-outcomes would be related to the likelihood to share revenge porn. This relationship was partially supported within the overall model with expected partner outcomes, but not expected self-outcomes, being positively related to the likelihood to share revenge porn. Boon, Deveau, and Alibhai (2009) revealed the primary motive for getting even against a romantic partner was to cause a desired changed in their partner. Participants in that study indicated correction, suffering and empathy as the changes they wanted to elicit from their partner. Those outcomes are similar to expected partner outcomes in the current study and are comparable to the Boon et al. study in that the present participants were also primarily likely to seek revenge against their romantic partners to cause a desired change within them. Less popular in Boon et al.'s study were desires to restore selfesteem and social reputation. Those outcomes closely relate to four out of the six expected self-outcomes in this study. In the study by Boon et al., fewer participants identified acts that threaten one's reputation or self-esteem as significant provocations that might lead to revenge. This could explain why in this study participants were less likely to pursue these types of revenge goals as well.

It was hypothesized that vengefulness would be related to one's motivation to seek positive expected partner and self-outcomes. These predictions were validated. It can be concluded that those who have a disposition to seek revenge are more likely to perceive the benefits of sharing revenge porn of their romantic partner following a provocation. These findings are consistent with past research that has examined the role of vengefulness and the benefits of getting revenge. For example, McCullough et al. (2001) established that highly vengeful people are less forgiving than others and overtime maintain motivations to seek revenge against those who provoke them. Likewise, Sheppard and Boon (2012) demonstrated that dispositionally vengeful people often view revenge as an attractive response to a provocation because they place more value on the benefits of seeking revenge. 
It was also hypothesized that a person's technological self-efficacy for sharing revenge porn would be related to their motivation to seek expected partner and self-outcomes. SCT projects that in order to achieve the positive outcomes of a given behavior one must actually know how to perform that behavior. It was therefore predicted that individuals who were motivated to seek the rewards of revenge porn sharing would need to have the technological capability to share revenge porn in order to achieve those rewards. This hypothesis was surprisingly not confirmed. The sample used for this study consisted of college students. College students continue to be early adopters of new Internet tools and applications in comparison to the general U.S. Internet-using population (Jones, Johnson-Yale, Millermaier, \& Perez 2009; Vishwanath \& Goldhaber, 2003). It is possible that the participants in this study all shared common beliefs for using the technology to disseminate revenge porn,therefore, making them invariant across the sample. Future studies might employ a more diverse sample to achieve greater variance.

The fourth hypothesis in this study predicted a relationship between vicarious experience and expected partner and self-outcomes. This hypothesis was not supported. The positive outcomes experienced by other revenge porn senders were predicted to be related to the same positive outcomes one might seek when deciding to share revenge porn. For instance, if a person who has been provoked by their romantic partner wants to humiliate their partner by sharing their sexual images, they may be influenced by someone they see who has also humiliated their partner by sharing revenge porn.

Although vicarious experience was not related to expected outcomes, vicarious influence wasdirectly related to the likelihood to share revenge porn.These findings partially support SCT that claims that people who observe other individuals gain desired outcomes by performing a specific behavior may be more inclined to mimic that behavior (Bandura, 1986). It is possible that the outcomes predicted in this study do not match the obtained outcomes of other individuals who have shared revenge porn. This might help explain the confounding results of hypothesis 4 and 5. When observing another person's behavior, there must be a certain level of success that is observed to influence similar behaviors in others (Bandura, 1986). Results of hypothesis 5 confirm this theoretical conjecture and shows that participants are more likely to 
share revenge porn based on external influences. Despite the non-significant relationship between vicarious influence and expected outcomes in this study, it is still suspected that participants must have acknowledged some sort of positive rewards attributed to sharing revenge porn. As Bandura (1986) comments, if a particular outcome has no incentive value for observers, then exposure to the vicarious influence will have negligible effects. Future research may consider additional dimensions of expected outcomes. This study was restricted to only two dimensions. Other motivations for seeking romantic revenge could include restoring the balance of power in the relationship (Boon et al., 2009; Miller \& Vidmar, 1994; Solomon, 1994), increasing the power in a relationship and repairing the damaged reputation of the relationship itself (Boon et al., 2009).

A test for moderating effects was also performed to determine if individuals who were faced with a high provocation condition would be more motivated to share revenge porn of their partner. It was predicted that the effect of the likelihood to share revenge porn would be stronger for those whose partner hypothetically cheated on them than for those whose partner hypothetically forgot to fulfill a promise to call them on the phone. Contrary to this prediction, the effect between expected partner outcomes and the likelihood to share revenge porn was not significantly different between the groups. The effect between expected selfoutcomes and likelihood to share revenge porn, however, was significantly different and therefore stronger for individuals in the low provocation condition. It can be suggested then that participants are more likely to be motivated to share revenge porn by outcomes that reduce negative feelings after they experience a provocation of a mild nature.

In this study, anger felt by participants was intended to differentiate between the severity of both conditions. Independent sample t-tests confirmed that those in the high provocation condition experienced higher levels of anger than those in the low condition. It is possible that participants in the low severity condition felt an emotion not related to anger that could have motivated their desire for revenge. For instance, sadness and humiliation are both emotions felt by people who perceive themselves to be victims of unjust treatment (Fridja, 1994; Mikulincer \& Shaver, 2005; Williamson \& Gonzalez; 2007).Previous studies have alsoshown that is the 
trivial and often, everyday provocation that cause the most significant damage to individuals (e.g. Andersson \& Pearson, 1999; Johnson \& Indvik, 2001). Specifically, the recurrence of seemingly mild transgressive acts may build overtime causing considerable dissatisfaction with the relationship, paving the way for revenge (Boon et al., 2009).

\section{Future Research and Limitations}

The current study controlled for gender, but future research should further examine whether there are gender differences in sharing revenge porn. A common misconception exists that victims of revenge porn are primarily female (cf. Stroud, 2014). Claiming that revenge porn primarily affects women more than men fits simple cultural narratives such as "slut-shaming" and fall into simple ideological approaches (see Citron \& Franks, 2014). Also, the current study only examined the benefits for sharing revenge porn but ignored the potential negative consequences for engaging in the behavior. Revenge can result in numerous adverse consequences including social stigma and feelings of guilt and shame (Boon et al., 2011) as well as legal repercussions. Future research should not only continue to examine what impels people to share revenge porn but it should also explore what inhibits people from sharing revenge porn as well.Additional studies should also examine the impact that an apology offered by a partner following a romantic provocation might have on the decision to share revenge porn. Gunderson and Ferrari (2008) found that individuals were more likely to forgive their romantic partners who cheated on them where the cheating was infrequenct and there was the presence of an apology.

Finally, thecurrent study was limited by the hypothetical nature of the provocation vignettes and the questionnaire that proceeded. There is of course a strong likelihood that individuals would react differently if placed in real life situations similar to the ones demonstrated by this study. Additionally, important variables in romantic relationships such as emotional investment and length of relationship should be examined in future studies to explore the effect of provocations further. 
Overall, this study lays initial empirical groundwork for the study of revenge porn and paves the way for future studies conducted on the subject. The results are useful here for researchers who want to contribute to this new area of research and are especially beneficial for those researchers who study romantic revenge and who wish to study this more explicit area of the field. 


\section{References}

Al-Gahtani, S., \& Hubona, G. W. (2007). Information technology in saudi arabia: Culture and the acceptance and use of IT. Information \& Management, 44, 681-691.

Andersson, L. M., \& Pearson, C. M. (1999).Tit for tat? The spiraling effect of incivility in the workplace. Academy of management review, 24, 452-471.

Aquino, K., \& Bradfield, M. (2000). Perceived victimization in the workplace: The role of situational factors and victim characteristics. Organization Science, 11(5), 525-537.

Authors. (2012). Sexually explicit user-generated content: Understanding motivations and behaviors using social cognitive theory. Cyberpsychology: Journal of Psychosocial Research on Cyberspace, 6(1). doi: 10.5817/CP2012-1-7

Authors. (2015). Problematic online pornography use: A media attendance perspective. Journal of Sex Research. Advance online publication. doi: 10.1080/00224499.2014.980496

Bachman, G. F., \& Guerrero, L. K. (2006). Relational quality and communicative responses following hurtful events in dating relationships: An expectancy violations analysis. Journal of Social and Personal Relationships, 23, 943-963.

Bandura, A. (1986). Social foundations of thought and action: A social cognitive theory. New Jersey: Prentice Hall.

Bandura, A. (2004). Social cognitive theory for personal and social change by enabling media. Entertainment-education and social change: History, research, and practice, 75-96.

Bandura, A. (2009). Social cognitive theory of mass communication. In J. Bryant, \& M. Oliver Media effects: Advances in theory and research (pp. 94-125). New York: Routledge.

Barnes, C. D., Brown, R. P., \& Osterman, L. L. (2009).Protection, payback, or both? Emotional and motivational mechanisms underlying avoidance by victims of transgressions. Motivation and Emotion, 33, 400-411.

Baumeister, R. (1997). Evil. New York: Freeman.

Benight, C. C., \& Bandura, A. (2004). Social cognitive theory of posttraumatic recovery: The role of perceived self-efficacy. Behaviour research and therapy, 42, 1129-1148. 
Bhakar, S. S., Bhakar, S., Bhakar, S., \& Sharma, G. (2012). The impact of co-branding on customer evaluation of brand extension. Prestige International Journal of Management \& IT, 1, 21-53.

Bies, R. J., \& Tripp, T. M. (1996). Beyond distrust:" Getting even" and the need for revenge. In R. Kramer \& T. Tyler et al. (Eds.), Trust in organizations, (pp. 246-260). Thousand Oaks, CA: Sage.

Bies, R. J., Tripp, T. M., \& Kramer, R. M. (1997). At the breaking point: Cognitive and social dynamics of revenge in organizations. In J. Greenberg \& R. Giacalone (Eds.), Antisocial behavior in organizations (pp.18-36). Thousand Oaks, CA: Sage.

Boies, S. C. (2002). University students' uses of and reactions to online sexual information and entertainment: Links to online and offline sexual behaviour. The Canadian Journal of Human Sexuality, 11, 77.

Boon, S. D., Alibhai, A. M., \& Deveau, V.L. (2011). Reflections on the costs and benefits of exacting revenge in romantic relationships. Canadian Journal of Behavioral Science, 43, 128-137.

Boon, S. D., Deveau, V. L., \& Alibhai, A. M. (2009). Payback: The parameters of revenge in romantic relationships. Journal of Social and Personal Relationships, 26, 747-768.

Brees, J. R., Mackey, J., \& Martinko, M. J. (2013). An attributional perspective of aggression in organizations. Journal of Managerial Psychology, 28(3), 252-272.

Brose, L. A., Rye, M. S., Lutz-Zois, C., \& Ross, S. R. (2005).Forgiveness and personality traits. Personality and Individual Differences, 39, 35-46.

Bull, S. S., McFarlane, M., Lloyd, L., \& Rietmeijer, C. (2004). The process of seeking sex partners online and implications for STD/HIV prevention. AIDS care, 16(8), 10121020.

Buzzell, T. (2005). Demographic characteristics of persons using pornography in three technological contexts. Sexuality \& Culture, 9(1), 28-48.

Carmines, E. G., \& Zeller, R. A. (1979). Reliability and validity assessment (Vol. 17). Sage publications.

Chin, W. (1998). The partial least square approach to structural equation modeling. MIS Quarterly, 22, 7-16. 
Chin, W., \& Newsted, P. R. (1999). Structural equation modeling: Analysis with small samples using partial least squares. In R. H. (Ed.), Statisical Strategies for Small Sample Research (pp. 307-341). Thousand Oaks, CA: Sage.

Citron, D. K., \& Franks, M. A. (2014, October 13). Criminalizing Revenge Porn. Retrieved from http://digitalcommons.law.umaryland.edu/fac_pubs/1420/

Cloke, K. (1993). Revenge, forgiveness, and the magic of mediation. Conflict Resolution Quarterly, 11, 67-78.

Cohen, J. (1988). Statistical power analysis for the behavioral sciences (2nd ed.). Hillsdale, NJ: Erlbaum.

Connolly, J., Craig, W., Goldberg, A., \& Pepler, D. (2004). Mixed-Gender Groups, Dating, and Romantic Relationships in Early Adolescence. Journal of Research on Adolescence, 14, 185-207.

Couch, D., \& Liamputtong, P. (2008). Online dating and mating: The use of the internet to meet sexual partners. Qualitative Health Research, 268-279.

Cyber Civil Rights Initiative (2013). Effects of revenge porn survey. Retrieved from http://www.cybercivilrights.org/end_revenge_porn_infographic

Deveau, V. L., \& Fouts, G. T. (2005). Revenge in US and Canadian news magazines post 9/11. Canadian Journal of Communication, 30.

Diamond, M. (2009). Pornography, public acceptance and sex related crime: A review. International Journal of Law and Psychiatry, 32, 304-314.

Dickerman, C., Christensen, J., \& Kerl-McClain, S. B. (2008). Big breasts and bad guys: Depictions of gender and race in video games. Journal of Creativity in Mental Health, 3, 20-29.

Doring, N. M. (2009). The Internet's impact on sexuality: A critical review of 15 years research. Computers in Human Behavior, 5, 1089-1101.

Douglas, S. C., \& Martinko, M. J. (2001). Exploring the role of individual differences in the prediction of workplace aggression. Journal of Applied Psychology, 86, 547.

Drouin, M., \& Landgraff, C. (2012). Texting, sexting, and attachment in college students' romantic relationships. Computers in Human Behavior, 28, 444-449.

Errante, A. (2003). Where in the world do children learn 'bloody revenge'?: Cults of terror and counter-terror and their implications for child socialisation. Globalisation, Societies and Education, 1, 131-152. 
Exline, J. J., Worthington, E. L., Hill, P., \& McCullough, M. E. (2003). Forgiveness and justice: A research agenda for social and personality psychology. Personality and Social Psychology Review, 7, 337-348.

Filipovoc, J. (2013, January 28). Revenge porn is about degrading women sexually and professionally. The Guardian. Retrieved from http://www.theguardian.com/commentisfree/2013/jan/28/revenge-porndegradeswomen

Finkel, E. J., Rusbult, C. E., Kumashiro, M., \& Hannon, P. A. (2002). Dealing with betrayal in close relationships: Does commitment promote forgiveness?.Journal of personality and social psychology, 82, 956.

Flannagan, D., Marsh, D. L., \& Fuhrman, R. (2005).Judgments about the hypothetical behaviors of friends and romantic partners. Journal of Social and Personal Relationships, 22, 797-815.

Frijda, N. H. (1994). The lextalionis: On vengeance. Emotions: Essays on emotion theory, 263289.

Fornell, C., \& Larcker, D. (1981). Evaluating structural equation models with unobservable variables and measurement error. Journal of Marketing, 18, 39-50.

Fornell, C., \& Cha, J. (1994). Partial least squares. In R. B. (Ed.), Advanced Methos of Marketing Research (pp. 52-78). New York: Oxford.

Fornell, C., \& Bookstein, F. (1982). Two structural equation models: LISREL and pls applied to consumer exit-voice theory. Journal of Marketing Research, 19, 440-452.

Franks, M. A. (2013). Criminalizing Revenge Porn: A Quick Guide. Available at SSRN.

Gabriel, M. A., \& Monaco, G. W. (1994).“Getting even”: Clinical considerations of adaptive and maladaptive vengeance.Clinical social work journal, 22, 165-178.

Glomb, T. M., \& Liao, H. (2003). Interpersonal aggression in work groups: Social influence, reciprocal, and individual effects. Academy of Management Journal, 46, 486-496.

Gunderson, P. R., \& Ferrari, J. R. (2008). Forgiveness of sexual cheating in romantic relationships: Effects of discovery method, frequency of offense, and presence of apology. North American Journal of Psychology, 10, 1-14.

Grov, C. (2006). Barebacking websites: electronic environments for reducing or inducing HIV risk. AIDS care, 990-997. 
Hazan, C., \& Shaver, P. (1987). Romantic love conceptualized as an attachment process. Journal of personality and social psychology, 52, 511.

Henseler, J., Dijkstra, T. K., Sarstedt, M., Ringle, C. M., Diamantopoulos, A., Straub, D. W., \& Calantone, R. J. (2014). Common beliefs and reality about pls comments on Rönkkö and Evermann (2014). Organizational Research Methods, 7, 182-209.

Hulland, J. (1999) Use of Partial Least Squares (PLS) in strategic management research: a review of four recent studies. Strategic Management Journal, 20, 195-204.

Innala, S. (2007). Pornography on the net: Same attraction, but new options. Sexologies, 16, 112-120.

Jayson, S. (2008, December 9). Study shows many teens, young adults share nude images. Retrieved December 10, 2009, from ABC News: http://abcnews.go.com/US/story?id=6433047\&page $=1$

Johnson, P. R., \& Indvik, J. (2001). Rudeness at work: Impulse over restraint. Public personnel management, 30, 457-465.

Jones, S., Johnson-Yale, C., Millermaier, S., \& Pérez, F. S. (2009). US college students' Internet use: Race, gender and digital divides. Journal of ComputerMediated Communication, 14, 244-264.

Kane, G. C., Alavi, M., Labianca, G., \& Borgatti, S. P. (2014). What's different about social media networks? A framework and research agenda. Mis Quarterly, 38, 275-304.

Kotler, J. A., \& Calverf, S. L. (2003). Children's and Adolescents' Exposure to Different Kinds of Media Violence: Recurring Choices and Recurring. Media violence and children: A complete guide for parents and professionals, 22, 171.

LaRose, R., \& Eastin, M. (2004). A social cognitive theory of Internet uses and gratifications: Toward a new model of media attendance. Journal of Broadcasting and Electronic Media, 48, 358-376.

Leary, M. R., Koch, E. J., \& Hechenbleikner, N. R. (2001).Emotional responses to interpersonal rejection. Interpersonal rejection, 145-166.

Levin, M., Lillis, J., \& Hayes, S. (2012). When is online pornography viewing problematic among college males? Examining the moderating role of experiential avoidance. Sexual Addiction \& Compulsivity, 19, 168-180. 
Liau, A., Millett, G., \& Marks, G. (2006). Meta-analytic examination of online sex-seeking and sexual risk behavior among when have sex with men. Sexually Transmitted Diseases, 33, 576-584.

Linkroum, S. C. (2009). Parents and Peers as Moderators of the Relation between Peer Victimization and the Development of Revenge Goals in Middle School Students (Doctoral dissertation, Virginia Commonwealth University Richmond, Virginia).

"Lovers beware: Scorned exes may share intimate data and images online." (2013, February 4).

McAfee. Retrieved from http://www.mcafee.com/us/about/news/2013/q1/20130204-01.aspx

Maltby, J., Macaskill, A., \& Day, L. (2001). Failure to forgive self and others: A replication and extension of the relationship between forgiveness, personality, social desirability and general health. Personality and Individual Differences, 30, 881-885.

McCullough, M., Bellah, C., Kilpatrick, S., \& Johnson, J. (2001). Vengefulness: Relationships with forgiveness, rumination, well-being, and the big five. Society for Personality and Social Psychology, 5, 601-610.

McCullough, M. E., Worthington Jr., E. L., \& Rachal, K. C. (1997).Interpersonal forgiving in close relationships. Journal of personality and social psychology, 73, 321.

McCullough, M. E., \& WitvlietvanOyen, C. (2001).The psychology of forgiveness. In C.R. Snyder (Ed.), Handbook of Positive Psychology (pp. 446-458). New York: Oxford University Press.

McDonald, K. L., \& Asher, S. R. (2013). College students' revenge goals across friend, romantic partner, and roommate contexts: The role of interpretations and emotions. Social Development, 22, 499-521.

McLean Parks, J. (1997). The fourth arm of justice: The art and science of revenge. In R. J. Lewicki, R. J. Bies, \& B. H. Sheppard (Eds.), Researchon negotiation in organizations (Vol. 6, pp. 113-144). Greenwich, CT: JAI Press.

Metts, S., \& Cupach, W. R. (2007). Responses to relational transgressions: Hurt, anger, and sometimes forgiveness. The dark side of interpersonal communication, 2, 243-274.

Miller, D. T. (2001). Disrespect and the experience of injustice. Annual Review of Psychology, $52,527-553$.

Mikulincer, M., \& Shaver, P. R. (2005).Attachment security, compassion, and altruism. Current directions in psychological science, 14, 34-38. 
Morse, C. R., \& Metts, S. (2011). Situational and communicative predictors of forgiveness following a relational transgression. Western Journal of Communication, 75, 239-258.

Nathanson, C., Williams, K. M., \& Paulhus, D. L. (2004, May). Don’t get mad, get even: Psychopaths' reactions to interpersonal provocations. In Poster presented at the annual meeting of the Association for Psychological Science, Montreal, Quebec.

National Conference of State Legislatures.(2014). State 'revenge porn' legislation. Retrieved from https://owl.english.purdue.edu/owl/resource/560/10/

Nunnally, J. (1978). Psychometric Theory. New York: McGraw Hill.

Ohbuchi, K. I., Kameda, M., \& Agarie, N. (1989). Apology as aggression control: its role in mediating appraisal of and response to harm. Journal of personality and social psychology, 56(2), 219.

Ozer, E. M., \& Bandura, A. (1990). Mechanisms governing empowerment effects: a self efficacy analysis. Journal of personality and social psychology, 58, 472.

Peterson, R. A., \& Kim, Y. (2013). On the relationship between coefficient alpha and composite reliability. Journal of Applied Psychology, 98, 194-198.

Philaretou, A., Mahfouz, A., \& Allen, K. (2005). Use of internet pornography and men's wellbeing. International Journal of Men's Health, 4, 149-169.

Rasmussen, K. (2013). Vengeful decisions: The role of perceived effectiveness and costliness of revenge (unpublished doctoral dissertation). University of Calgary. Calgary, Alberta.

Rasmussen, K. R., \& Boon, S. D. (2014). Romantic revenge and the Dark Triad: A model of impellance and inhibition. Personality and Individual Differences, 56, 51-56.

Reinartz, W., Haenlein, M., \& Henseler, J. (2009).An empirical comparison of the efficacy of covariance-based and variance-based SEM. International Journal of research in Marketing, 26, 332-344.

Restubog, S. L. D., Zagenczyk, T. J., Bordia, P., Bordia, S., \& Chapman, G. J. (2012). If You Wrong Us, Shall We Not Revenge? Moderating Roles of Self-Control and Perceived Aggressive Work Culture in Predicting Responses to Psychological Contract Breach. Journal of Management.

Ringle, C. (2005). Smart PLS. Version Beta 2.0. Hamburg, Germany. 
Roseman, I. J., Wiest, C., \& Swartz, T. S. (1994). Phenomenology, behaviors, and goals differentiate discrete emotions. Journal of Personality and Social Psychology, 67, 206.

Runions, K. C. (2013). Toward a conceptual model of motive and self-control in cyberaggression: rage, revenge, reward, and recreation. Journal of youth and adolescence, $1-21$.

Rusbult, C. E., Verette, J., Whitney, G. A., Slovik, L. F., \& Lipkus, I. (1991). Accommodation processes in close relationships: Theory and preliminary empirical evidence. Journal of Personality and Social Psychology, 60, 53.

Schumann, K., \& Ross, M. (2010).The benefits, costs, and paradox of revenge. Social and Personality Psychology Compass, 4, 1193-1205.

Seabright, M. A., \& Schminke, M. (2002). Immoral imagination and revenge in organizations. Journal of Business Ethics, 38, 19-31.

Seigfried, K., Lovely, R., \& Rogers, M. (2008). Self-reported online child pornography behavior: a psychological analysis. International Journal of Cyber Criminology, 2, 286-297.

Shaver, P., \& Mikulincer. (2006). Attachment theory, individual psychodynamics, and relationship functioning. In A. V. (Eds), The Cambridge handbook of personal relationships (pp. 251-271). New York: Cambridge University Press.

Sheppard, K., \& Boon, S. D. (2012). Predicting appraisals of romantic revenge: The roles of Honesty-Humility, Agreeableness, and vengefulness.Personality and Individual Differences, 52, 128-132.

Skarlicki, D. P., \& Folger, R. (1997). Retaliation in the workplace: The roles of distributive, procedural, and interactional justice. Journal of applied Psychology, 82, 434.

Solomon, R. C. (1990). A passion for justice: Emotions and the origins of the social contract. Reading, MA: Addison-Wesley.

Stroud, S. R. (2014). The Dark Side of the Online Self: A Pragmatist Critique of the Growing Plague of Revenge Porn. Journal of Mass Media Ethics, 29(3), 168-183.

Stuckless, N., \& Goranson, R. (1992). The Vengeance Scale: Development of a measure of attitudes toward revenge. Journal of Social Behavior \& Personality. 
Tripp, T. M., \& Bies, R. J. (1997). What's good about revenge? In R. J. Lewicki, R. J. Bies \& B.H. Sheppard (Eds.), Research on negotiation in organizations, Vol 6 (pp. 145-160). Greenwich, CT: JAI Press.

Twohig, M., Crosby, J., \& Cox, J. (2009). Viewing Internet Pornography: For Whom is it Problematic, How, and Why? Sexual Addiction and Compulsivity, 16, 253-266.

Vishwanath, A., \& Goldhaber, G. M. (2003). An examination of the factors contributing to adoption decisions among late-diffused technology products. New Media \& Society, 5, 547-572.

Walker, D. F., \& Gorsuch, R. L. (2002).Forgiveness within the Big Five personality model. Personality and Individual Differences, 32, 1127-1137.

Williams, K. M., Cooper, B. S., Howell, T. M., Yuille, J. C., \&Paulhus, D. L. (2009). Inferring Sexually Deviant Behavior From Corresponding Fantasies The Role of Personality and Pornography Consumption. Criminal Justice and Behavior, 36, 198-222.

Williamson, I., \& Gonzales, M. H. (2007). The subjective experience of forgiveness: Positive construals of the forgiveness experience. Journal of Social and Clinical Psychology, $26,407-446$.

Yoshimura, S. (2007). Goals and emotional outcomes of revenge activities in interpersonal relationships. Journal of Social and Personal Relationships, 24, 87-98.

Zehnder, S. M., \& Calvert, S. L. (2004). Between the hero and the shadow: Developmental differences in adolescents' perceptions and understanding of mythic themes in film. Journal of Communication Inquiry, 28, 122-137. 